\title{
Spatial patterns of extra-pair paternity in a waterbird colony: separating the effects of nesting density and nest site location
}

\author{
Piotr Minias $^{1}$ - Katarzyna Wojczulanis-Jakubas ${ }^{2} \cdot$ Robert Rutkowski $^{3}$ • \\ Krzysztof Kaczmarek $^{4}$ - Tomasz Janiszewski ${ }^{1}$
}

Received: 24 September 2015 / Revised: 27 December 2015 / Accepted: 29 December 2015 /Published online: 14 January 2016

(C) The Author(s) 2016. This article is published with open access at Springerlink.com

\begin{abstract}
Centres of avian colonies are usually associated with reduced predation risk and, thus, attract individuals of high quality, while poor-quality individuals are relegated to peripheral zones. Assuming that the incidence of extra-pair paternity (EPP) is dependent on individual quality, we could expect lower incidence of extra-pair offspring in the central parts of colonies. On the other hand, central pairs often nest in higher densities, which might increase EPP rate. To test these hypotheses, we sampled 124 great cormorant Phalacarocorax carbo sinensis chicks from 30 broods from different zones of a colony and genotyped them at seven highly polymorphic microsatellite loci. Sibship reconstruction confirmed the presence of at least one extra-pair chick in $30.0 \%$ of broods. We found that EPP varied significantly between the zones of the
\end{abstract}

Communicated by C. R. Brown

Significance statement Females often seek extra-pair copulations with males of higher genetic quality than their mates to gain indirect genetic benefits for their offspring ('good genes' hypothesis). As poor-quality pairs usually occupy low-quality breeding sites, we might expect more extra-pair paternity (EPP) in less attractive territories. There is scant information on EPP distribution in avian colonies. We predicted that the incidence of EPP should (1) decrease in the attractive, better protected, central parts of the colonies and (2) increase with nesting density. To test these predictions, we molecularly assessed occurrence of EPP within a colony of great cormorants. We showed that the incidence of EPP was higher in the peripheral zone of the colony, while it was not related to the local nesting density. The study provides the first evidence for the centreedge difference in EPP within a breeding colony of birds.

\section{Piotr Minias}

pminias@biol.uni.lodz.pl

1 Department of Teacher Training and Biodiversity Studies, University of Łódź, Banacha 1/3, 90-237 Łódź, Poland colony, with higher incidence of extra-pair broods in the peripheral zone (53.3 vs. $6.7 \%$ of broods). Centre-edge difference in EPP was consistent with the expected distribution of pair quality and suggested that poor-quality peripheral females were more likely to solicit extra-pair interactions, possibly to gain 'good genes' for their offspring. By contrast, we found no evidence for density dependence in EPP rate, indicating that likelihood of raising extra-pair offspring was not constrained by limited availability of local males. The results indicate that spatial randomization of sampling within avian colonies is critical to obtain robust estimations of EPP for non-solitary species. To our knowledge, this study provides the first evidence for the centre-edge difference in EPP within a breeding colony of birds.
2 Department of Vertebrate Ecology and Zoology, University of Gdańsk, Wita Stwosza 59, 80-308 Gdańsk, Poland

3 Department of Molecular and Biometrical Techniques, Museum and Institute of Zoology PAS, 00-679 Warsaw, Poland

4 Medical University of Łódź, Sterlinga 1/3, 91-425 Łódź, Poland 
Keywords Coloniality · Great cormorant · Microsatellites . Phalacrocorax carbo sinensis $\cdot$ Sibship reconstruction

\section{Introduction}

Extra-pair paternity (EPP) has been recorded in about $90 \%$ of all bird species, demonstrating that a large majority of socially monogamous birds show varying degrees of promiscuity (Griffith et al. 2002; Neudorf 2004). Variation in EPP between major avian lineages is best explained by differences in fundamental life history traits (Møller 2000; Arnold and Owens 2002), while variation between closely related species or populations is usually explained by contemporary ecological factors (Stutchbury and Morton 1995; Petrie et al. 1998; Gohli et al. 2013). However, within populations, the frequency of solicited extra-pair copulations and resulting fertilizations may also depend on individual quality. The 'good genes' hypothesis assumes that females seek extra-pair copulations (EPCs) with males of higher genetic quality than their mates to gain indirect genetic benefits (viability genes or genes for attractiveness) for their offspring (Kempenaers et al. 1992; Strohbach et al. 1998). Under this scenario, poor-quality females, which usually mate assortatively with poor-quality males (Andersson et al. 1998; García-Navas et al. 2009), would be more likely to raise extra-pair offspring. As poorquality pairs are likely to occupy low-quality nest sites (Sergio et al. 2009), we might expect more EPP in less attractive territories or nest sites, providing that high-quality males are available in the neighbourhood as potential extra-pair sires (Schlicht et al. 2015).

While some information exists on the spatial patterns of EPP in territorial birds (Bollinger and Gavin 1991; FreemanGallant et al. 2005; Westneat and Mays 2005), very little is known about how extra-pair offspring are distributed within colonies. In many colonial species, especially those that breed in relatively homogeneous habitats (Minias 2014), central parts of the colonies are most attractive and offer the highest benefits in terms of fitness. Centrally located nests are usually less susceptible to predation due to the following: (1) lower accessibility for most types of predators and (2) more efficient detection and deterrence of predators in the colony centre (Götmark and Andersson 1984; Yorio and Quintana 1997). For this reason, individuals of higher quality are likely to occupy safer central nest sites and individuals of lower quality are relegated to less attractive edge sites, resulting in a socalled central-periphery gradient of pair quality (Velando and Freire 2001). Central-periphery gradients in pair quality have been reported for many colonial species from diverse taxonomic groups, such as cormorants, larids, pelicans, penguins and procellarids (reviewed in Minias 2014). One of the first studies to demonstrate a central-periphery gradient found that central breeding pairs of Black-legged Kittiwakes Rissa tridactyla were in better physical condition and had higher fledging success than peripheral pairs (Coulson 1968). Further research on this species showed that centrally nesting individuals had higher survival rates than conspecifics occupying peripheral nest sites (Aebischer and Coulson 1990). In many colonial species, central pairs have been reported to breed earlier (Côté 2000; Gibbs et al. 2000), lay larger clutches (Montevecchi 1978; Gochfeld 1980) and raise chicks in better condition (Minias et al. 2012b). These patterns were often attributed to older birds with more experience (Blus and Keahey 1978; Pugasek and Diem 1983; Vergara and Aguirre 2006) or individuals with higher genetic quality (Minias et al. 2015a) nesting in the centre of colonies. Thus, under the assumptions of the good genes hypothesis, it might be expected that central-periphery patterns in pair quality should produce similar gradients in the incidence of extra-pair offspring and, thus, a greater proportion of extra-pair offspring in the peripheral parts of the colonies.

On the other hand, EPP rate may also be density-dependent, as both sexes are expected to have more opportunities for EPCs at higher breeding densities (Mougeot 2004). While the positive impact of local breeding densities on EPP has been demonstrated for some territorial passerines (Charmantier and Perret 2004; Stewart et al. 2010; Mayer and Pasinelli 2013), it is often debated whether EPP is related to density in most avian populations (Westneat and Sherman 1997; Tarof et al. 1998; Rätti et al. 2001). For example, it has been suggested that density effects are more likely if males control extra-pair fertilizations and females are passive targets of insemination (Dunn et al. 1994). While this may be the case in many colonial birds (Nelson 2005), there is scarce information on whether local breeding densities may affect EPP in species that breed in aggregations. Also, since central parts of the colonies are often associated with higher breeding densities (e.g., Becker 1995), the effects of central-periphery nest position and local density may easily be confounded.

The aim of this study was to investigate spatial patterns in EPP within a colony of the great cormorant Phalacrocorax carbo sinensis. A number of fitness-related traits follow a central-periphery gradient in great cormorant colonies, consistent with higher quality of central breeding pairs (e.g., Andrews and Day 1999; Minias et al. 2012a, b; Minias and Kaczmarek 2013). Also, unlike most colonial waterbirds with slow life histories, the great cormorant has a relatively high rate of EPP, averaging $16 \%$ across several populations (Piertney et al. 2003). These characteristics make the great cormorant a suitable species to test hypotheses on the within-colony spatial variation in EPP. We predicted that the distribution of EPP within a colony would show the following: (1) lower incidence of extra-pair offspring in the central parts of the colony in comparison to the peripheral zone (consistent with the good genes hypothesis) and (2) higher incidence of extra-pair offspring in higher nesting densities. To 
test these predictions, we used a set of highly polymorphic microsatellite loci to identify extra-pair offspring and, then, conducted a spatial analysis which separated the effects of nest location and density on the rate of EPP.

\section{Material and methods}

\section{Study site and species}

The study was conducted in a colony of great cormorants at Jeziorsko reservoir $\left(51^{\circ} 73^{\prime} \mathrm{N}, 18^{\circ} 63^{\prime} \mathrm{E}\right)$, central Poland, in 2010-2011. The colony was located in the area of riparian willow woodland dominated by the white willow Salix alba and the grey willow Salix cinerea in the vicinity of Proboszczowice village $\left(51^{\circ} 43.39^{\prime} \mathrm{N}, 18^{\circ} 38.61^{\prime} \mathrm{E}\right)$ at the western shore of the reservoir. Great cormorants started to breed at Jeziorsko reservoir in 1991, when 90 nesting pairs were recorded at the site. Since then, the location and spatial organization of the colony have changed over time, and in 2010-2011, birds bred in two separate colonies at the reservoir. The colony chosen for this study was established in 2005 by ca. 40 cormorant pairs and held ca. 150 pairs in 2010 2011.

This subspecies of the great cormorant breeds colonially at a wide spectrum of inland waters throughout Europe and Asia. European populations are mostly migratory, and courtship and pair formation takes place shortly after arrival on the breeding grounds, usually in March. Breeding is relatively synchronized (peak laying in April-May in Europe), and pairs only have one brood per season. Replacement clutches may occur if the first clutch is lost but are unlikely after the loss of young (Nelson 2005).

\section{Nest site location and nesting density}

Each year, all active nests were mapped with a handheld Global Positioning System (GPS) unit (Garmin GpsMap $60 \mathrm{Cx}$, Olathe, KS, USA) with European Geostationary Navigation Overlay Service (EGNOS) ensuring accuracy of 1-1.5 m. Collected coordinates were used to calculate distances between all the nests in the colony. On the basis of the nest-distance matrices, we calculated two measures of nesting density: (1) small-scale nesting density (nest density within a radius of $5 \mathrm{~m}$ of each nest) and (2) large-scale nesting density (nest density within a radius of $15 \mathrm{~m}$ of each nest). All the nests were also assigned to either the central or peripheral zone of the colony. Since the shape of the colony was irregular and all the pairs clustered around a central open-water pond, the nests located within a distance of $20 \mathrm{~m}$ from the pond were considered central, while all other nests were considered peripheral (Fig. 1). Using a threshold distance of $20 \mathrm{~m}$ allowed us to obtain a roughly equal division of nests between the zones, with 43.6 and $46.0 \%$ of all nests assigned to the central zone in 2010 and 2011, respectively.

\section{Field procedures}

The colony was visited from mid-March, when first pairs initiated laying. Laying dates and clutch sizes were recorded for 50 broods per year. Laying was relatively synchronized, and the large majority of clutches were laid by the end of April in both years. For the purpose of paternity analyses, we randomly selected at hatching 30 broods with 124 offspring (14 broods in 2010, 16 broods in 2011; all hatched between 14 April and 09 May). Only broods where all eggs hatched successfully were selected. Broods were equally distributed among the central and peripheral zones of the colony (15 broods per zone), and the mean size of the sampled broods was $4.13 \pm 0.11$ [SE] (range 3-6) offspring. Within each zone, we sampled broods from a wide spectrum of nesting densities (large-scale nesting density range $1-15$ vs. $1-13$ nests/15-m radius in the central and peripheral zone, respectively), which allowed us to separate the effects of nesting density and central-periphery nest location on EPP rate. As a result of this sampling design, our set of selected broods showed no significant differences in an average nesting density between the central and peripheral zones of the colony (small-scale nesting density $1.53 \pm 0.50$ vs. $1.60 \pm 0.35$ nests $/ 5$-m radius, $t=0.11$, $d f=28, p=0.91$; large-scale nesting density $5.53 \pm 1.08$ vs. $6.73 \pm 1.04$ nests $/ 15$-m radius, $t=0.80, d f=28, p=0.43$ ). Peripheral nests from the south-eastern part of the colony were excluded from sampling (Fig. 1), as they were largely inaccessible to researchers. To minimize the problem of non-independence, we avoided selecting the same nest sites in both seasons. Great cormorants have high nest site fidelity (Schjørring et al. 2000), so this likely excluded repeated measurements of the same pairs. Blood samples (ca. $10 \mu \mathrm{l}$ ) were collected soon after hatching by puncturing the ulnar vein of nestlings. The samples were immediately suspended in $96 \%$ ethanol and stored until laboratory analyses.

\section{Genetic analysis}

For genotyping, we used seven microsatellite loci previously developed for the great cormorant (Piertney et al. 1998). Forward primers were labelled with fluorescent dyes (D2, D3, D4, Sigma-Aldrich, Poland). We used a multiplex PCR Kit (Qiagen) in $15-\mu \mathrm{L}$ total volume to simultaneously amplify five loci (PcD 4, PcD 6, PcT 1, PcT 3, PcT 4). A separate PCR was used to amplify the two other loci (PcD 2, PcD 5) using Polimerease mix (Sigma-Aldrich) in $25-\mu \mathrm{L}$ total volume. We used a $55^{\circ} \mathrm{C}$ annealing for both types of reactions. We genotyped the PCR products using a Beckman Coulter CEQ 8000 capillary automated sequencer at the Museum and Institute of Zoology, Polish Academy of Science (Warsaw, Poland). We 
Fig. 1 A map of the great cormorant colony at Jeziorsko reservoir, central Poland. Darkshaded area marks the central pond, light-shaded areas mark riparian willow woodland, and the dashed line bounds the central zone of the colony. Nests sampled for paternity are marked with large squares, where opened squares indicate broods with no extra-pair chicks and filled squares indicate broods with at least one extra-pair chick. Dots mark active nests not sampled for paternity analyses

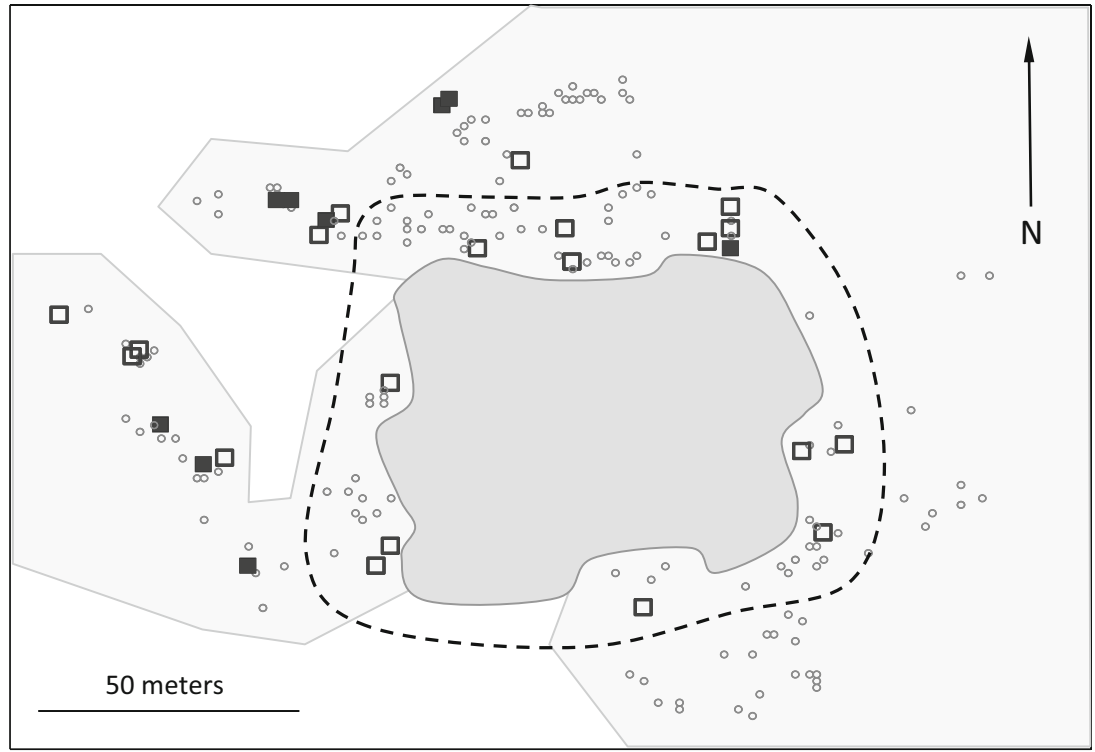

scored alleles visually using the Beckman Coulter Fragment Analysis Software. The mean number of alleles per locus was 26.3 (10-53 alleles), and observed heterozygosity ranged from 0.57 to 1.00 (details for larger dataset in Minias et al. 2015b). The combined non-exclusion probability for sib identity was $4.17 \times 10^{-4}$, as calculated in Cervus 3.0.3 (Kalinowski et al. 2007).

\section{Estimating EPP}

We did not collect DNA from parents, so to determine the number of extra-pair young, we used two methods of sibship reconstruction among the nestlings. Firstly, we used a maximum likelihood method implemented in the program COLONY v2.0 (Wang 2004) to partition nestlings into fulland half-sib clusters. Maximum likelihood partitioning is considered more powerful than the pairwise approach because more information on entire families rather than just pairs of individuals is extracted and utilized (Wang and Santure 2009). In the analysis, the error rate of genotyping was set to 0.025 as suggested by Wang (2004). We did not allow for multiple maternity within broods, as despite a large body of molecular paternity studies in Phalacrocorax genus and other genera from Suliformes order (Graves et al. 1993; Baumgarten et al. 2001; Dearborn et al. 2001; Anderson and Boag 2006; Baião and Parker 2009; Calderón et al. 2012), no sound empirical evidence was found for either conspecific brood parasitism or quasi parasitism in this group of birds (reviewed in Yom-Tov 2001; Griffith et al. 2004). Secondly, we tested for full-sibling relationships using likelihood ratio tests based on Queller and Goodnight's $r$ (Queller and Goodnight 1989; Goodnight and Queller 1999) implemented in KINGROUP v2 (Konovalov et al. 2004). To identify extra-pair chicks within broods, a primary hypothesis of full siblings was tested against a null hypothesis of half siblings. Ten thousand simulations were carried out to assess the significance of likelihood ratios $(p<0.05)$. Only the chicks for which the results of both methods matched (indicated half-sib relationships with nest mates) were considered to result from extra-pair fertilizations.

\section{Statistical analyses}

We used a generalized linear model with a binomial distribution and logit link function to test for the effects of nest site location (binary response: central vs. peripheral zone) and nesting density on the occurrence of extra pair paternity. Broods were used as the unit of the analysis, and binary codes were assigned for each response category of the dependent variable $(0-$ no extra-pair offspring, 1 -at least one extrapair offspring). Small- and large-scale nesting densities were log-transformed prior to the analysis to improve normality. Both measures of density showed only moderate correlation ( $r=0.48, n=30, p=0.007)$ and, thus, were included as covariates into one model without violating the assumption of little/ no multicollinearity $(|r|<0.8)$ in the data. The effect of year was entered as a fixed factor, and laying date was entered as a covariate in the models. Stepwise procedures of backward removal were used to select for significant independent variables, and their significance was determined using the Wald $\chi^{2}$ statistic. All statistical analyses were performed with STATISTICA 10.0 (StatSoft, Tulsa, OK, USA).

\section{Results}

Based on the sibship reconstruction, $30.0 \%$ of broods were classified as containing at least one extra-pair offspring $(n=30)$, and in total, $10.5 \%$ of chicks were identified as 
resulting from extra-pair fertilizations $(n=124)$. In five out of nine extra-pair broods, only one chick per brood was classified as extra-pair, while in the other four broods, two chicks per brood were classified as extra-pair.

The occurrence of EPP differed significantly between the zones of the colony, and there was a higher incidence of extrapair broods in the peripheral compared to the central zone (53.3 vs. $6.7 \%$; Wald $\chi^{2}=5.60, d f=1, p=0.018$; Fig. 1 ). By contrast, the EPP rate did not vary with nesting density. Neither small- nor large-scale nesting density had significant effects on the occurrence of EPP (small-scale density: Wald $\chi^{2}=0.39, d f=1, p=0.53$; large-scale density: Wald $\chi^{2}=0.66$, $d f=1, p=0.42$; Fig. 2). Consistently, we found no effect of nesting density on the occurrence of EPP when the analysis was restricted to the peripheral zone, where nearly $90 \%$ of extra-pair broods were recorded (small-scale density: Wald $\chi^{2}=0.07, d f=1, p=0.79$; large-scale density: Wald $\chi^{2}=1.57, d f=1, p=0.21$; Fig. 2). Occurrence of EPP did

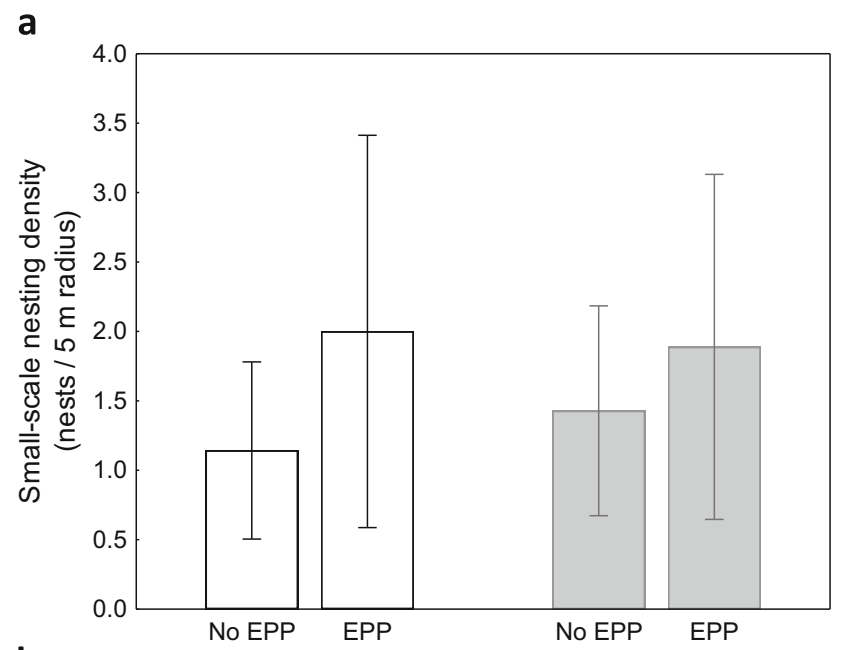

b

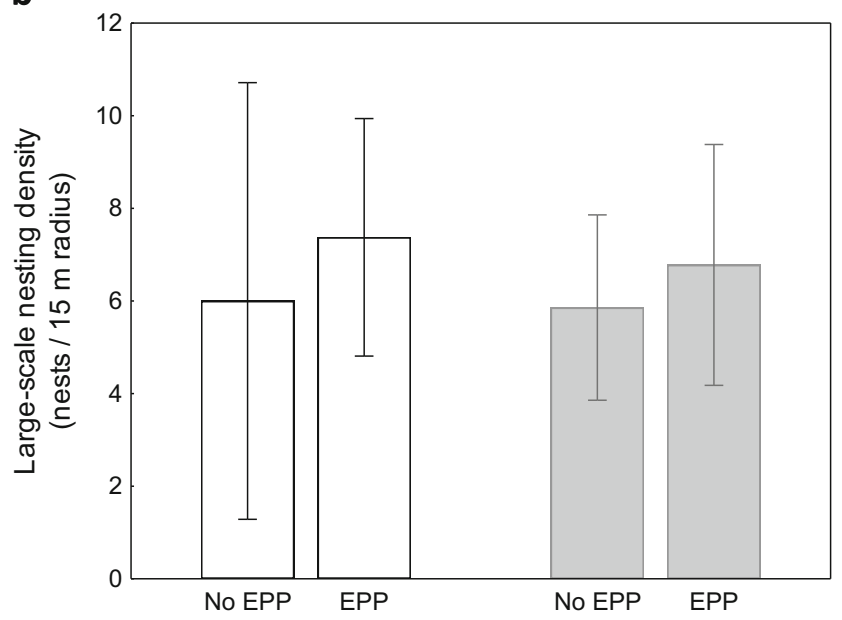

Fig. 2 Nesting density of broods with no extra-pair chicks (no EPP) and with extra-pair chicks (EPP) in the colony of the great cormorant; shown separately for the peripheral zone of the colony (white bars) and for the entire colony (shaded bars) at small- (a) and large-scale (b) nesting densities. Means $\pm 95 \%$ confidence intervals are shown not differ between years (Wald $\chi^{2}=0.95, d f=1, p=0.33$ ) and did not vary with laying date (Wald $\chi^{2}=0.00, d f=1$, $p=0.99$ ).

\section{Discussion}

In this study, we confirmed the occurrence of the centre-edge difference in EPP within a colony of great cormorants. Most of the broods with extra-pair offspring were recorded in the peripheral part of the colony, while incidence of EPP in the central zone was negligible. By contrast, we found no effect of density on the level of EPP.

Although estimates of EPP are available for many colonial waterbirds, spatial analyses of EPP distribution within colonies are scarce, and we are aware of no study that tested for the central-periphery pattern of EPP distribution within a breeding colony of birds. A recent study of the colonial blue-footed booby Sula nebouxii showed that the spatial variation of EPP across a colony was determined by habitat structure (number of obstacles to locomotion) and was quadratically related to breeding density (Ramos et al. 2014). It was proposed that individuals nesting at intermediate density were most likely to be accessed by males foraying for EPCs, while obstacles in the vicinity of a female's nest constrained the access of foraying males (Ramos et al. 2014). These patterns have been attributed to habitat complexity (forest floor with embedded boulders and remains of dead trees) that restricted birds' movements throughout the colony.

While the centre-edge difference in EPP has not been tested in the blue-footed booby, there was some indication for the good genes hypothesis in this species, as extra-pair courtship was more common in females with younger mates (Kiere and Drummond 2014). Strong support for the good genes hypothesis was also found for the European shag Phalacrocorax aristotelis. It has been shown that the reproductive success of females is correlated negatively with the number of solicited EPCs and that the most successfully reproducing males attracted more females to their territories for EPCs (Graves et al. 1993). Although we had no direct information on the quality of adult birds in our colony, there is relatively strong empirical evidence for the poorer quality of peripherally nesting pairs. Previous studies in the same colony indicated that peripheral pairs started breeding later and raised fewer fledglings than central pairs (Minias et al. 2012a; Minias and Kaczmarek 2013). Peripheral pairs were also younger (Minias 2012), and they invested more in female offspring, which are smaller and, thus, less expensive to rear (Minias et al. 2014b). Taking all of these previous results into account, we suggest that the centre-edge difference in EPP rate is due to poorquality peripheral females seeking genetic benefits for their offspring via extra-pair matings. 
We also found that the EPP rate in the great cormorant was not related to local nesting density. This may suggest that females do not engage in EPCs with closest neighbours but seek interactions with males from more distant, possibly central, parts of the colony. A similar mechanism has been described in the blue-footed booby, where extra-pair chicks were not sired by neighbours (Ramos et al. 2014). Spatial patterns of EPP in other colonial birds seem to support a general lack of density effects, although there is limited information available. No relationship between local nesting density and individual numbers of EPCs has been reported for a colonial white ibis Eudocimus albus (Frederick 1987), and the number of extra-pair fertilizations was not related to nesting density in a mixed colony of Ross's geese Chen rossi and lesser snow geese Chen caerulescens (Dunn et al. 1999). Lack of density effects in geese has been attributed to the ability of females to resist EPCs and control the success of extra-pair fertilizations. Under this mechanism, greater density may not increase the benefits of EPP to females, because adding more potential mates will not necessarily increase opportunities for extrapair matings, at least above a minimum level of density (Dunn et al. 1999). We hypothesize that a similar mechanism may explain the lack of relationship between EPP and nesting density in the great cormorant.

Our estimation of EPP rate in the great cormorant (ca. 10\% of offspring) is among the highest ever recorded in colonial waterbirds. More extra-pair offspring per brood have been reported only in two species, the waved albatross Phoebastria irrorata (Huyvaert et al. 2000) and the blackheaded gull Chroicocephalus ridibundus (Ležalová-Piálková 2011). High EPP rate in the great cormorant is surprising, as this species is characterized by relatively slow life history. Adult survival rate was estimated at $0.88-0.90$ for the $P h . c$. sinensis subspecies (Frederiksen and Bregnballe 2000; Hénaux et al. 2007), which translates into an average lifespan of 6 years (Schjørring et al. 2000). It is predicted that in such long-lived species, abandonment of a reproductive event is likely to be adaptive under uncertainty of paternity (Mauck et al. 1999), thus, constraining the evolution of a high EPP rate. Nevertheless, some other life history traits of the great cormorant do not clearly fit into the pattern of slow life history. Most importantly, great cormorants have relatively high fecundity driven primarily by a large clutch size (on average, three to four eggs), which distinguishes this species from most seabirds (Bregnballe 2006). As large clutch size decreases the risk of retaliation via divorce, it could possibly facilitate the occurrence of elevated EPP rate (Arnold and Owens 2002).

To our knowledge, this study provides the first evidence for the centre-edge difference in EPP within a breeding aggregation of birds. The spatial distribution of EPP was consistent with the expected distribution of pair quality within the colony and suggested that poor-quality peripheral females were more likely to solicit extra-pair interactions to gain good genes for their offspring. The results may have important practical consequences for further research on EPP in colonial species, indicating that spatial randomization of brood sampling within the colonies is critical to obtain robust estimations of EPP.

Acknowledgments We are very grateful to Bartosz Lesner, Anna Piasecka and Radosław Włodarczyk for their help with the fieldwork. We also thank Peter O. Dunn, Charles R. Brown (Associate Editor) and an anonymous reviewer for their constructive suggestions on the earlier draft of the manuscript. The study was supported by the grants from the University of Gdańsk (BW/L120-5-0422-0) and from the Ministry of Science and Higher Education in Poland (N N303 319940).

\section{Compliance with ethical standards}

Ethical standards The study was performed under the permissions of the Bioethical Commission and the Regional Environmental Protection Directorate in Łódź, Poland.

Conflict of interest The authors declare no conflict of interest.

Open Access This article is distributed under the terms of the Creative Commons Attribution 4.0 International License (http:// creativecommons.org/licenses/by/4.0/), which permits unrestricted use, distribution, and reproduction in any medium, provided you give appropriate credit to the original author(s) and the source, provide a link to the Creative Commons license, and indicate if changes were made.

\section{References}

Aebischer NJ, Coulson JC (1990) Survival of the kittiwake in relation to sex, year, breeding experience and position in the colony. J Anim Ecol 59:1063-1071

Anderson DJ, Boag PT (2006) No extra-pair fertilization observed in Nazca Booby (Sula granti) broods. Wilson J Ornithol 118:244-247

Andersson S, rnborg J, Andersson M (1998) Ultraviolet sexual dimorphism and assortative mating in blue tits. Proc R Soc Lond B 265: 445-450

Andrews DJ, Day KR (1999) Reproductive success in the Cormorant Phalacrocorax carbo carbo in relation to colony nest position and timing of nesting. Atl Seabirds 1:107-120

Arnold KE, Owens IPF (2002) Extra-pair paternity and egg dumping in birds: life history, parental care and the risk of retaliation. Proc R Soc Lond B 269:1263-1269

Baião PC, Parker PG (2009) No evidence of extra-pair fertilization in redfooted boobies (Sula sula). Waterbirds 32:179-182

Baumgarten MM, Kohlrausch AB, Miyaki CY, Ochotorena de Freitas TR, de Araújo Mellender A (2001) DNA fingerprinting and parentage in masked (Sula dactylatra) and brown (S. leucogaster) boobies. Ornitol Neotrop 12:319-326

Becker PH (1995) Effects of coloniality on gull predation on Common Tern (Sterna hirundo) chicks. Waterbirds 18:11-22

Blus LJ, Keahey JA (1978) Variation in reproductive success with age in the Brown Pelican. Auk 95:128-134

Bollinger E, Gavin T (1991) Patterns of extra-pair fertilizations in bobolinks. Behav Ecol Sociobiol 29:1-7

Bregnballe T (2006) Age-related fledgling production in great cormorants Phalacrocorax carbo: influence of individual competence and disappearance of phenotypes. J Avian Biol 37:149-157 
Calderón L, Svagelj WS, Quintana F, Lougheed SC, Tubaro PL (2012) No evidence of extra-pair paternity or intraspecific brood parasitism in the Imperial Shag Phalacrocorax atriceps. J Ornithol 153:399404

Charmantier A, Perret P (2004) Manipulation of nest-box density affects extra-pair paternity in a population of blue tits (Parus caeruleus). Behav Ecol Sociobiol 56:360-365

Côté SD (2000) Aggressiveness in King Penguins in relation to reproductive status and territory location. Anim Behav 59:813-821

Coulson JC (1968) Differences in the quality of birds nesting in the center and on the edges of a colony. Nature 217:478-479

Dearborn DC, Anders AD, Parker PG (2001) Sexual dimorphism, extrapair fertilizations, and operational sex ratio in great frigatebirds (Fregata minor). Behav Ecol 12:746-752

Dunn PO, Whittingham LA, Lifjeld JT, Robertson RJ, Boag PT (1994) Effects of breeding density, synchrony, and experience on extrapair paternity in tree swallows. Behav Ecol 5:123-129

Dunn PO, Afton AD, Gloutney ML, Alisauskas RT (1999) Forced copulation results in few extrapair fertilizations in Ross's and lesser snow geese. Anim Behav 57:1071-1081

Frederick PC (1987) Extrapair copulations in the mating system of white ibis (Eudocimus albus). Behaviour 100:170-201

Frederiksen M, Bregnballe T (2000) Evidence for density-dependent survival in adult cormorants from a combined analysis of recoveries and resightings. J Anim Ecol 69:737-752

Freeman-Gallant C, Wheelwright N, Meiklejohn K, States SL, Sellecito SV (2005) Little effect of extrapair paternity on the opportunity for sexual selection in the savannah sparrows (Passerculus sandwichensis). Evolution 59:422-430

García-Navas V, Ortego J, Sanz JJ (2009) Heterozygosity-based assortative mating in blue tits (Cyanistes caeruleus): implications for the evolution of mate choice. Proc R Soc Lond B 276:2931-2940

Gibbs HM, Norman FI, Ward SJ (2000) Reproductive parameters, chick growth and adult 'age' in Australasian Gannets Morrus serrator breeding in Port Philip Bay, Victoria, in 1994-95. Emu 100:175185

Gochfeld M (1980) Timing of breeding and chick mortality in central and peripheral nests of Magellanic Penguins. Auk 97:191-193

Gohli J, Anmarkrud JA, Johnsen A, Kleven O, Borge T, Lifjeld JT (2013) Female promiscuity is positively associated with neutral and selected genetic diversity in passerine birds. Evolution 67:1406-1419

Goodnight KF, Queller DC (1999) Computer software for performing likelihood tests of pedigree relationship using genetic markers. Mol Ecol 8:1231-1234

Götmark F, Andersson M (1984) Colonial breeding reduces nest predation in the Common Gull (Larus canus). Anim Behav 32:485-492

Graves J, Ortega-Ruano J, Slater PJB (1993) Extra-pair copulations and paternity in shags: do females choose better males? Proc R Soc Lond B 253:3-7

Griffith SC, Owens IPF, Thuman KA (2002) Extra pair paternity in birds: a review of interspecific variation and adaptive function. Mol Ecol 11:2195-2212

Griffith SC, Lyon BE, Montgomerie R (2004) Quasi-parasitism in birds. Behav Ecol Sociobiol 56:191-200

Hénaux V, Bregnballe T, Lebreton J-D (2007) Dispersal and recruitment during population growth in a colonial bird, the great cormorant Phalacrocorax carbo sinensis. J Avian Biol 38:44-57

Huyvaert KP, Anderson DJ, Jones TC, Duan W, Parker PC (2000) Extrapair paternity in Waved Albatrosses. Mol Ecol 9:1415-1419

Kalinowski ST, Taper ML, Marshall TC (2007) Revising how the computer program CERVUS accommodates genotyping error increases success in paternity assignment. Mol Ecol 16:1099-1106

Kempenaers B, Verheyen GR, Van den Broeck M, Burke T, Vam Broeckhoven C, Dhondt AA (1992) Extra-pair paternity results from female preference for high-quality males in the blue tit. Nature 357:494-496
Kiere LM, Drummond H (2014) Extrapair behaviour reveals flexible female choosiness and mixed support for classic good genes in blue-footed boobies. Anim Behav 95:145-153

Konovalov DA, Manning C, Henshaw MT (2004) KINGROUP: a program for pedigree relationship reconstruction and kin group assignments using genetic markers. Mol Ecol Notes 4:779-782

Ležalová-Piálková R (2011) Molecular evidence for extra-pair paternity and intra-specific brood parasitism in the Black-headed Gull. J Ornithol 152:291-295

Mauck RA, Marschall EA, Parker PG (1999) Adult survival and imperfect assessment of parentage: effects on male parenting decisions. Am Nat 154:99-109

Mayer C, Pasinelli G (2013) New support for an old hypothesis: density affects extra-pair paternity. Ecol Evol 3:694-705

Minias P (2012) Factors responsible for within-colony spatial variation in reproductive parameters of Great Cormorant Phalacrocorax carbo sinensis. $\mathrm{PhD}$ thesis, University of Łódź, Poland

Minias P (2014) Evolution of within-colony distribution patterns in birds in response to habitat structure. Behav Ecol Sociobiol 68:851-859

Minias P, Kaczmarek K (2013) Is it always beneficial to breed in the center? Trade-offs in nest site selection within the colony of a treenesting waterbird. J Ornithol 154:945-953

Minias P, Kaczmarek K, Janiszewski T (2012a) Distribution of pair quality in a tree-nesting waterbird colony: central-periphery model vs. satellite model. Can J Zool 90:861-867

Minias P, Lesner B, Janiszewski T (2012b) Nest location affects chick growth rates in Whiskered Terns Chlidonias hybrida. Bird Study 59: 372-375

Minias P, Wojczulanis-Jakubas K, Kaczmarek K (2014) Offspring sex ratio varies according to nest location within a colony of Great Cormorants. Auk 131:388-395

Minias P, Minias A, Dziadek J (2015a) Heterozygosity correlates with body size, nest site quality and productivity in a colonial waterbird, the whiskered tern (Chlidonias hybrida, Aves: Sternidae). J Zool Syst Evol Res 53:133-139

Minias P, Wojczulanis-Jakubas K, Rutkowski R, Kaczmarek K (2015b) Local heterozygosity effects on nestling growth and condition in the great cormorant. Evol Biol 42:452-460

Møller AP (2000) Male parental care, female reproductive success and extra-pair paternity. Behav Ecol 11:161-168

Montevecchi WA (1978) Nest site selection and its survival value among laughing gulls. Behav Ecol Sociobiol 4:143-161

Mougeot F (2004) Breeding density, cuckoldry risk and copulation behaviour during the fertile period in raptors: a comparative analysis. Anim Behav 67:1067-1076

Nelson JB (2005) Pelicans, cormorants, and their relatives. In: The Pelecaniformes. Oxford University Press, New York

Neudorf DLH (2004) Extra-pair paternity in birds: understanding variation among species. Auk 121:302-307

Petrie M, Doums C, Møller AP (1998) The degree of extra-pair paternity increases with genetic variability. Proc Natl Acad Sci U S A 95: 9390-9395

Piertney SB, Goostrey A, Dallas JF, Carss DN (1998) Highly polymorphic microsatellite markers in the great cormorant Phalacrocorax carbo. Mol Ecol 7:138-140

Piertney SB, Carss DN, Goostrey A (2003) Population variation in the frequency of extra-pair paternity in the great cormorant Phalacrocorax carbo. Vogelwelt 124(Suppl):149-155

Pugasek BH, Diem KL (1983) A multivariate study of the relationship of parental age to reproductive success in California Gulls. Ecology 64: 829-839

Queller DC, Goodnight KF (1989) Estimating relatedness using genetic markers. Evolution 43:258-275

Ramos AG, Nunziata SO, Lance SL, Rodrígues C, Faircloth BC, Gowaty PA, Drummond H (2014) Habitat structure and colony structure 
constrain extrapair paternity in a colonial bird. Anim Behav 95:121127

Rätti O, Lundberg A, Tegelström H, Alatalo RV (2001) No evidence for effects of breeding density and male removal on extrapair paternity in the pied flycatcher. Auk 188:147-155

Schjørring S, Gregersen J, Bregnballe T (2000) Sex difference in criteria determining fidelity towards breeding sites in the great cormorant. $\mathrm{J}$ Anim Ecol 69:214-223

Schlicht L, Valcu M, Kempenaers B (2015) Spatial patterns of extra-pair paternity: beyond paternity gains and losses. J Anim Ecol 84:518-531

Sergio F, Blas J, Baos R, Forero MG, Donázar JA, Hiraldo F (2009) Short-and long-term consequences of individual and territory quality in a long-lived bird. Oecologia 160:507-514

Stewart SLM, Westneat DF, Ritchison G (2010) Extra-pair paternity in eastern bluebirds: effects of manipulated density and natural patterns of breeding synchrony. Behav Ecol Sociobiol 64:463-473

Strohbach S, Curio E, Bathen A, Epplen JT, Lubjuhn T (1998) Extrapair paternity in the great tit (Parus major): a test of the "good genes" hypothesis. Behav Ecol 9:388-396

Stutchbury BJ, Morton ES (1995) The effect of breeding synchrony on extra-pair mating systems in songbirds. Behaviour 132:675-690
Tarof SA, Stuchbury BJ, Piper WH, Fleischer RC (1998) Does breeding density covary with extra-pair fertilizations in hooded warblers? J Avian Biol 29:145-154

Velando A, Freire J (2001) How general is the central-periphery distribution among seabird colonies? Nest spatial pattern in the European Shag. Condor 103:544-554

Vergara P, Aguirre JI (2006) Age and breeding success in relation to nest position in a White Stork Ciconia ciconia colony. Acta Oecol 30: 414-418

Wang J (2004) Sibship reconstruction from genetic data with typing errors. Genetics 166:1963-1979

Wang J, Santure AW (2009) Parentage and sibship inference from multilocus genotype data under polygamy. Genetics 181:1579-1594

Westneat DF, Mays H (2005) Tests of spatial and temporal factors influencing extra-pair paternity in red-winged blackbirds. Mol Ecol 14:2155-2167

Westneat DF, Sherman PW (1997) Density and extra-pair fertilizations in birds: a comparative analysis. Behav Ecol Sociobiol 41:205-215

Yom-Tov Y (2001) An updated list and some comments on the occurrence of intraspecific nest parasitism in birds. Ibis 143:133-143

Yorio P, Quintana F (1997) Predation by Kelp gulls Larus dominicanus at a mixed-species colony of royal terns Sterna maxima and Cayenne terns Sterna eurygnatha in Patagonia. Ibis 139:536-541 